\title{
CARACTERIZAÇÃO FÍSICA E QUÍMICA DE SOLO EM SISTEMAS DE MANEJO PLANTIO DIRETO E CONVENCIONAL
}

Jhonata Santos Santana ${ }^{1}$, Elton Ferreira Lima ${ }^{2}$, Rogério Shinichi Komatsu ${ }^{3}$, Wilson Araújo da Silva ${ }^{4}$, Maria Ivanessa Duarte Ribeiro ${ }^{5}$

1. Bolsista de Apoio Técnico Institucional II (BATI II), Engenheiro Agrônomo, Universidade Estadual do Maranhão-UEMA. Imperatriz, MA. agro.starf@gmail.com

2. Bolsista de iniciação científica, Graduando em Engenharia Agronômica, Universidade Estadual da Região Tocantina do Maranhão-UEMASUL, Imperatriz, MA.

3. Graduado em Engenharia Agronômica na Universidade Estadual da Região Tocantina do Maranhão-UEMASUL, Imperatriz, MA.

4. Doutor em Ciência do Solo, Engenheiro Agrônomo, Universidade Estadual do Maranhão, Imperatriz, MA.

5. Bolsista de iniciação científica, Graduanda em Engenharia AgronômicaUniversidade Estadual da Região Tocantina do Maranhão-UEMASUL, Imperatriz, MA.

\section{Recebido em: 06/04/2018 - Aprovado em: 10/06/2018 - Publicado em: 20/06/2018} DOI: 10.18677/EnciBio_2018A26

\section{RESUMO}

Sabendo que o manejo inadequado do solo é um dos principais fatores que promovem sua degradação e a queda na produção das lavouras. O objetivo deste estudo foi avaliar os impactos causados por diferentes sistemas de cultivo, plantio direto e convencional, nas propridades físicas e químicas de um Argissolo VermelhoAmarelo em uma propriedade localizada no município de Açailândia-MA, onde foram coletadas amostras através do anel de Kopecky nas profundidades de $0,00-0,10$, $0,10-0,20,0,20-0,30$ e $0,30-0,40 \mathrm{~m}$. O delineamento utilizado foi o inteiramente casualizado (DIC) com dois tratamentos (plantio direto e convencional), quatro profundidades e cinco repetições, totalizando 40 parcelas experimentais. Foram analisadas as variáveis: densidade real (Ds), densidade de partículas (Dp), porosidade total $(\mathrm{Pt})$, umidade com base em massa $(\mathrm{U})$ e umidade volumétrica $(\mathrm{Q})$ para cada parâmetro avaliado foi realizada a análise de variância e comparação de médias pelo teste Tukey a $5 \%$ de probabilidade. Além disso, foram realizados testes de compactação por meio de penetrômetro e coletadas amostras de solo nos sistemas de manejo e enviadas para laboratório para a realização de análises químicas e físicas. Os resultados mostram que os dois anos de utilização do plantio direto ainda não foram capazes de promover alterações significativas nas propriedades de densidade do solo e porosidade, no entanto comprova que o emprego desse sistema contribui para o acúmulo de matéria orgânica no solo e armazenamento de água, além de proporcionar incrementos nos valores de $\mathrm{P}, \mathrm{K}^{+}$, $\mathrm{Ca}^{2+}, \mathrm{Mg}^{2+}$ e matéria orgânica em relação ao sistema de plantio convencional.

PALAVRAS-CHAVE: densidade do solo, matéria orgânica, plantio direto, sistema de cultivo 


\title{
PHYSICAL CHARACTERIZATION AND SOIL CHEMISTRY IN NO-TILLAGE AND CONVENTIONAL TILLAGE SYSTEMS
}

\begin{abstract}
Knowing that the inefficient management of the soil is one of the main factors that promote its degradation and the fall in the production of the crops. The objective of this work was to evaluate the impacts caused by different systems of cultivation, notillage and conventional tillage, on the physical and chemical properties of a Alfisol in farm located in the municipality of Açailândia-MA, where samples were collected through of the Kopecky ring at depths of $0,00-0,10,0,10-0,20,0,20-0,30$ e $0,30-$ $0,40 \mathrm{~m}$. The design was the completely randomized (DIC) with two treatments (notillage and conventional tillage), four depths and five replications, totaling 40 experimental plots. The variables: bulk density (Ds), particle density (Dp), total porosity (Ps), mass-based humidity (U) and volumetric humidity $(\mathrm{Q})$ were analyzed for each parameter evaluated by analysis of variance and comparison of means by the Tukey test at $5 \%$ probability. In addition, compaction tests were performed using a penetrometer and soil samples were collected in the management systems and sent to the laboratory for chemical and physical analysis. The results show that the two years of no-tillage utilization has not yet been able to promote significant changes in bulk density and porosity properties, however, it has been shown that the use of this system contributes to the accumulation of organic matter in the soil and water storage, in addition to increasing the values of $\mathrm{P}, \mathrm{K}^{+}, \mathrm{Ca}^{2+}, \mathrm{Mg}^{2+}$ and organic matter in relation to conventional tillage system.
\end{abstract}

KEYWORDS: Bulk density, organic matter, no-tillage, cropping system

\section{INTRODUÇÃO}

O sistema de manejo plantio direto (SPD) surgiu em meados da década de1980 sendo empregado principalmente em lavouras de grãos como soja, milho e trigo e apresenta grande capacidade de melhorar a produção agrícola, além de contribuir para minimizar os impactos dos sistemas agrícolas sobre o meio ambiente, pela redução da erosão do solo e da lixiviação (PERIN et al., 2015).

As áreas de cultivo sob SPD vêm aumentando consideravelmente em razão dos benefícios proporcionados, uma vez que o não revolvimento do solo e a manutenção da palhada evitam erosão, lixiviação, além de proporcionar maior infiltração de água e manter o solo úmido, bem como melhorar a operacionalidade produtividade agrícola (DIAS et al., 2015). Vários estudos têm evidenciado que a adoção desse sistema de manejo, em substituição ao preparo convencional, contribui para a melhoria das características físicas, químicas e biológica do solo à medida que os cultivos forem se sucedendo, principalmente em razão da cobertura proporcionada, pelas plantas vivas e mortas, que contribuem para a redução da erosão, minimizando as perdas de água, solo e nutrientes além de promover o acúmulo de material orgânico na superfície do solo e redução das emissões de gases de efeito estufa (GEEs) (FAVARATO et al., 2015; OLIVEIRA et al., 2015; SANTOS et al., 2017; COLOMBO et al., 2017).

A região Oeste do estado do Maranhão apresenta excelente potencial para a agricultura, especialmente para produção de grãos de soja, milho e também a pecúaria e os capins que predominam neste sistema são as Braquiárias decumbens, ruziziensis, brizantha e as cultivares de Panicum maximun: Colonião, Tanzânia e Mombaça e pecuária com gado leiteiro e de corte. Entretanto, essas forrageiras, após alguns anos de uso, iniciam um rápido processo de queda de produção, que 
quase sempre resulta em degradação. Na maior parte dessas áreas, há a predominância de Argissolos e também Latossolos, ácidos e de baixa fertilidade natural, que na maioria das situações apresentam horizontes coesos, que impõem limitações ao desenvolvimento radicular. Além disso, nos cultivos da soja e do milho no oeste maranhense predomina o emprego de sistemas de manejo convencionais, caracterizados pelo revolvimento intensivo do solo através de aração e gradagens, que contribuem a intensificação de processos erosivos e de compactação do solo que resultam em rápida degradação física, química e biológica do solo (FREITAS et al., 2017).

A alternativa de recuperar as extensas áreas de pastagens degradadas, com o cultivo de grãos por meio de bases sustentáveis, como o plantio direto, na região Tocantina, pode contribuir para diminuir a pressão por desmatamento em novas áreas na região de transição Cerrado-Amazônia, reduzir problemas econômicos, ambientais e sociais. A adoção desse sistema de produção é considerado uma excelente alternativa para recuperar essas áreas, devido a sua capacidade de aumentar a matéria orgânica em perfil do solo (palhada), e cobertura do solo evitando a evaporação da água mantendo a temperatura estável, esses fatores são proporcionados exclusivamente, pelo sistema plantio direto que é capaz de manter a produção de grãos em níveis satisfatórios mesmo nos anos em que ocorrem veranicos (COLOMBO et al., 2017).

$\mathrm{Na}$ região Oeste do Maranhão, até então, não se tem informação sobre estudos de identificação de alterações nas propriedades físicas e químicas ocasionadas por diferentes sistemas de manejo e uso do solo. Estudos dessa natureza são de fundamental importância, pois fornecem um conjunto de informações preciosas a respeito do potencial de melhoria da qualidade física e química sob diferentes sistemas de manejo do solo. Além disso, também, são de suma importância para uma melhor compreensão da sustentabilidade em sistemas de cultivo de grãos em áreas de cerrado, fornecendo informações que possam servir como referência para avaliação e seleção de indicadores de qualidade do solo que podem ser avaliadas através das alterações ocorridas em seus atributos físicos e químicos (TORRES et al., 2015).

O conhecimento dos danos provocados pelos diferentes sistemas de manejo é essencial para melhorar as qualidades físicas e químicas do solo, isso porque o uso inadequado do solo como o revolvimento excessivo ou o uso de práticas pouco conservacionistas, podem provocar aumento da densidade, diminuição da macroporosidade e porosidade total dentre outros danos (SOARES et al., 2016). Diferentes atributos do solo têm sido empregados para caracterizar as modificações resultantes da adoção de diferentes manejos do solo. Os parâmetros utilizados comumente são a densidade e porosidade do solo (CARVALHO et al., 2014), densidade de partículas (BATISTA et al., 2017), umidade do solo (LIMA et al., 2015) resistência do solo à penetração (TAVARES et al., 2014), acumulação de nutrientes e matéria orgânica (MARTINS et al., 2015; GOMES et al., 2015).

Em regiões de transição cerrado-amazônia as práticas de manejo solo deve ser realizadas de forma a permitir a acumulação de resíduos vegetais em superfície, devendo ser empregados principalmente em áreas de cultivo de baixa fertilidade natural e de comum ocorrência de períodos secos (veranicos) especialmente durante as fases de formação da vagem e enchimento de grãos, pois os resíduos orgânicos contribuem para o aumento da fertilidade, proteção do solo, reteção e armazenamento de água das chuvas e redução da umidade por evapotranspiração. Assim, o presente estudo teve como objetivo identificar as principais alterações nas 
propriedades físicas e químicas do solo ocasionadas por diferentes sistemas de manejo.

\section{MATERIAL E MÉTODOS}

O estudo foi realizado em uma propriedade localizada no município de Açailândia-MA, onde são cultivados soja, milho e milheto. No entanto, a principal atividade do local de estudo é a produção da espécie leguminosa Glycine Max em que há dois anos adotou-se o sistema de manejo plantio direto (SPD). O solo foi classificado como Argissolo Vermelho - Amarelo localizado em formações de transição entre o Bioma Amazônico e o Cerrado em uma altitude de cerca de $300 \mathrm{~m}$. O clima do local é caracterizado como tropical quente e úmido, com duas estações bem definidas, sendo uma chuvosa compreendida no período de outubro a abril, e outra seca que compreende de maio a setembro, ou seja, possui um inverno seco e verão chuvoso.

Para avaliar a influência dos sistemas de uso e manejo do solo, foram coletadas amostras para caracterização física e química e realizados testes de compactação em duas áreas, sendo elas: área de manejo do solo com plantio direto e outra caracterizada com manejo de solo em sistema convencional, separadas a uma distância de $300 \mathrm{~m}$. As amostras foram coletadas em um ponto central da parcela, na entrelinha onde era cultivado o milho, e após a limpeza da superfície do terreno. A coleta para determinação das características físicas foi realizada em dezembro de 2017, depois da colheita do milho, nas camadas de 0,00-0,10, 0,10$0,20,0,20-0,30$ e $0,30-0,40 \mathrm{~m}$ de profundidade.

As amostras indeformadas para a determinação das análises físicas foram obtidas por meio do anel volumétrico de Kopecky em quatro profundidades, nos dois ambientes de manejo (sistema de plantio direto e sistema de plantio convencional), ou seja, dois tratamentos, quatro profundidades com cinco repetições, totalizando 40 unidades experimentais. Já as amostras para determinação das características químicas e matéria orgânica foram coletadas utilizando um trado tipo sonda e o índice de compactação, em ambos os sistemas de manejo do solo, foi determinado in locu utilizando um penetrômetro modelo Stolf com cinco repetições em cada ambiente.

Após da retirada das amostras, para as análises físicas e químicas, estas foram acondicionadas em caixas e identificadas e posteriomente encaminhadas ao laboratório. As amostras indeformadas obtidas com o anel volumétrico foram utilizadas para a determinação dos seguintes parâmetros físicos: densidade real ou aparente do solo (Ds), densidade de partículas (Dp), porosidade total (Pt), umidade com base em massa $(U)$, umidade volumétrica $(Q)$, de acordo com o manual de métodos de análises de solos (EMBRAPA, 1997).

$O$ delineamento experimental utilizado foi o inteiramente casualizado (DIC) com dois níveis de fatores, formado pelos fatores profundidade e sistemas de manejo. $O$ fator profundidade foi constituído por quatro níveis (diferentes profundidades) e o fator tipos de manejo foi constituído por dois níveis (plantio direto e plantio convencional) caracterizando um experimento bifatorial com cinco repetições $(4 \times 2 \times 5)$. Por se tratar de experimento com tratamentos qualitativos (diferentes sistemas de manejo de solo) as variáveis observadas foram submetidas à análise de variância e comparadas pelo teste de Tukey a $5 \%$ de probabilidade $(P \leq 5 \%)$ utilizando o pacote estatístico SISVAR 5.6.

Densidade do solo (Ds)

RESULTADOS E DISCUSSÃO 
Na Tabela 1 estão apresentadas as informações de densidades do solo (Ds) obtidas em diferentes profundidades nos sistemas de manejo plantio direto e convencional.

TABELA 1- Densidade do solo em $\mathrm{g} . \mathrm{cm}^{-3}$, obtida em diferentes profundidades nos sistemas plantio direto e convencional.

\begin{tabular}{|c|c|c|c|c|c|c|c|c|}
\hline \multirow[b]{2}{*}{$\begin{array}{c}\text { Repetiçõe } \\
\mathrm{S}\end{array}$} & \multicolumn{4}{|c|}{ Plantio Direto } & \multicolumn{4}{|c|}{ Plantio Convencional } \\
\hline & $\begin{array}{c}0 \\
-10 \mathrm{~cm} \\
\end{array}$ & $10-20 \mathrm{~cm}$ & $20-30 \mathrm{~cm}$ & $30-40 \mathrm{~cm}$ & $0-10 \mathrm{~cm}$ & $10-20 \mathrm{~cm}$ & $20-30 \mathrm{~cm}$ & $30-40 \mathrm{~cm}$ \\
\hline R1 & 1,08 & 1,09 & 1,19 & 1,09 & 1,05 & 1,18 & 1,24 & 1,21 \\
\hline R2 & 1, & & & 1, & & 1, & & 1, \\
\hline R3 & $1,0 \varepsilon$ & 1,17 & 1,2 & 1,16 & 1,02 & 1,1 & 1, & 1,20 \\
\hline R4 & 1,10 & 1,02 & 1,19 & 1,18 & 1,13 & 1,19 & 1,20 & 1,24 \\
\hline R5 & 1,07 & 1,08 & 1,20 & 0,99 & 1,12 & 1,14 & 1,19 & 1,18 \\
\hline
\end{tabular}

A densidade do solo é expressa pela razão entre a massa sólida e o volume total (volumes ocupados pelas partículas sólidas e pelos poros). Os valores médios de densidade do solo no sistema plantio direto (Tabela 1) variaram de 1,00 a 1,10 g. $\mathrm{cm}^{-3}$ na camada superficial de $0-10 \mathrm{~cm}$ e de 1,02 a $1,17 \mathrm{~g} . \mathrm{cm}^{-3}$ na camada subsuperficial de 10-20 cm. Já Cherubin et al. (2015) estudando a densidade de solos argilosos sob sistema plantio direto obtiveram valores de Ds variando de 1,40 a $1,51 \mathrm{~g} \cdot \mathrm{cm}^{-3}$ na camada superficial $(0-10 \mathrm{~cm})$ e de 1,30 a $1,50 \mathrm{~g} \cdot \mathrm{cm}^{-3}$ na camada subsuperficial $(10-20 \mathrm{~cm})$.

Os resultados obtidos nos sistemas de manejo plantio direto e convencional estão dentro dos padrões e níveis aceitáveis para esse tipo de solo, os argilosos, que normalmente variam de 0,90 a $1,25 \mathrm{~g} . \mathrm{cm}^{-3}$, sendo que valores de $D s>1,40 \mathrm{~g} . \mathrm{cm}^{-}$ ${ }^{3}$, são considerados restritivos para a maioria das culturas agrícolas em solos de textura argilosa (BALIN et al., 2017). Entretanto, nota-se através da análise da Tabela 1, que a densidade do solo em todas as profundidades avaliadas apresentaram valores próximos em ambos os sistemas de manejo estudados.

De modo geral, as menores densidades do solo foram observadas na camada de 0 a $10 \mathrm{~cm}$ e as maiores densidades ocorreram nas camadas de $20-30 \mathrm{~cm}$ no sistema plantio direto e 30-40 cm no sistema de manejo convencional (Tabela 2). De acordo com Silva et al. (2017) as menores densidades observadas nas camadas superficiais estão relacionadas à maior densidade de raízes das culturas agrícolas utilizadas e ao maior teor de matéria orgânica. Na Tabela 2 estão apresentados os resultados da ANOVA de densidades do solo (Ds) obtidas em diferentes profundidades nos diferentes sistemas de manejo pelo teste de Tukey.

TABELA 2- Resultados da média de densidade do solo (Ds) em $\mathrm{g}_{\mathrm{cm}} \mathrm{cm}^{-3}$ pelo teste de Tukey.

\begin{tabular}{ccccc}
\hline & \multicolumn{4}{c}{ Profundidades } \\
Tratamentos & $\mathbf{0 - 1 0} \mathbf{~ c m}$ & $\mathbf{1 0 - 2 0} \mathbf{~ c m}$ & $\mathbf{2 0 - 3 0} \mathbf{~ c m}$ & $\mathbf{3 0 -} \mathbf{4 0} \mathbf{~ c m}$ \\
\hline Plantio Direto & $1,06 \mathrm{a} 1$ & $1,10 \mathrm{a} 1$ & $1,19 \mathrm{a} 1$ & $1,10 \mathrm{a} 1$ \\
Plantio Convencional & $1,06 \mathrm{a} 1$ & $1,18 \mathrm{a} 2$ & $1,18 \mathrm{a} 1$ & $1,21 \mathrm{a} 2$ \\
CV\% & 4,50 & 3,87 & 3,21 & 4,83 \\
\hline
\end{tabular}

Legenda: $\mathrm{CV}$, Coeficiente de variação. Médias seguidas pela as mesmas letras e números nas colunas não diferem estatisticamente pelo Teste Tukey a $5 \%$ de probabilidade.

Os sistemas de manejo plantio direto (SPD) e convencional (SPC) nas profundidades de $0-10 \mathrm{~cm}, 20-30 \mathrm{~cm}$ não apresentaram diferença significativa em 
relação à densidade do solo (Ds), nas demais profundidades de $10-20 \mathrm{~cm}$ e 30 $40 \mathrm{~cm}$, houve diferença significativa, entretanto, os valores de densidades encontrados nos dois sistemas, ainda permaneceram bem próximos. Diante disso, nota-se que para este parâmetro, que o tempo de utilização do plantio direto ainda não foi capaz de modificar consideravelmente as características da Ds no horizonte superficial. Além disso, outros autores já encontraram valores de densidade do solo na camada superficial do SPC significativamente menor em relação ao SPD, como o verificado nos estudos de Toigo et al., (2015) que observaram maiores valores de densidade de solo na camada superficial do sistema plantio direto em relação ao SPC.

Negreiros Neto et al. (2014) estudando a densidade do solo em sistema plantio direto em áreas do cerrado tocantinense obtiveram o valor de $2,47 \mathrm{~g} . \mathrm{cm}^{-3}$ que é um valor elevado se comparado a outros trabalhos em condições de plantio direto em regiões do cerrado. Sendo que estes autores atribuíram esses resultados ao adensamento natural devido a ausência de revolvimento solo e também pela compactação provocada pelo tráfego de máquinas no SPD. Moraes et al. (2014) e López-Garrido et al. (2014) também observaram em seus estudos maiores densidades do solo do sistema plantio direto em relação ao preparo de solo convencional.

As densidades do solo semelhantes, observadas na camada superficial de 0$10 \mathrm{~cm}$, em ambos os sistemas de manejo, também podem ser atribuídas ao fato que no sistema plantio direto, apesar de ocorrer preparo do solo restrito à linha de semeadura, as máquinas continuam trafegando normalmente em toda extensão da área, o que favorece o adensamento das camadas superficiais do solo (ASSIS; LANÇAS, 2005; ASSIS et al., 2015).

A análise dos resultados da Tabela 2 também permite observar uma tendência de redução dos valores da densidade do solo (Ds) do sistema plantio direto em relação ao convencional, com o aumento da profundidade de amostragem, isto pode está relacionado ao fato de que os solos argilosos, quando são bastante trabalhado no sistema de manejo convencional, tende a ocorrer empacotamento e o adensamento do solo em profundidade. Além disso, também existe uma tendência de aumento dos valores desta variável, no sistema convencional, com a utilização da grade pesada.

\section{Densidade de partículas (Dp)}

Na Tabela 3 estão descritas as informações de densidades de partículas (Dp) obtidas em diferentes profundidades nos diferentes sistemas de manejo.

TABELA 3 - Densidade de partículas em g. $\mathrm{cm}^{-3}$, obtida em diferentes profundidades nos sistemas plantio direto e convencional.

\section{Plantio Direto}

\begin{tabular}{ccccccccc}
$\begin{array}{c}\text { Repetiçõe } \\
\text { s }\end{array}$ & $0-10 \mathrm{~cm}$ & $10-20 \mathrm{~cm}$ & $20-30 \mathrm{~cm}$ & $30-40 \mathrm{~cm}$ & $\begin{array}{c}0-10 \\
\mathrm{~cm}\end{array}$ & $10-20 \mathrm{~cm}$ & $20-30 \mathrm{~cm}$ & $30-40 \mathrm{~cm}$ \\
\hline R1 & 1,55 & 1,61 & 1,45 & 1,41 & 1,47 & 1,40 & 1,39 & 1,40 \\
R2 & 1,59 & 1,54 & 1,45 & 1,42 & 1,48 & 1,38 & 1,45 & 1,42 \\
R3 & 1,57 & 1,62 & 1,44 & 1,41 & 1,46 & 1,37 & 1,43 & 1,46 \\
R4 & 1,56 & 2,00 & 1,44 & 1,43 & 1,44 & 1,41 & 1,41 & 1,42 \\
R5 & 1,56 & 1,67 & 1,42 & 1,43 & 1,45 & 1,44 & 1,40 & 1,42 \\
\hline
\end{tabular}


A densidade de partículas pode ser definida como a razão entre a massa de uma amostra de solo e o volume ocupado pela partículas sólidas. Esta variável desconsidera a porosidade, levando em consideração somente as partículas sólidas da amostra.

$\mathrm{Na}$ Tabela 4 estão apresentados os resultados a ANOVA de densidades de partículas (Dp) obtidas em diferentes profundidades nos diferentes sistemas de manejo pelo teste de Tukey.

TABELA 4 - Resultados da média de densidade de partículas (Dp) em $\mathrm{g} \cdot \mathrm{cm}^{-3}$ pelo teste de Tukey.

\begin{tabular}{ccccc}
\hline & \multicolumn{4}{c}{ Profundidades } \\
Tratamentos & $\mathbf{0 - 1 0} \mathbf{~ c m}$ & $\mathbf{1 0 - 2 0} \mathbf{~ c m}$ & $\mathbf{2 0 - 3 0} \mathbf{~ c m}$ & $\mathbf{3 0 - 4 0} \mathbf{~ c m}$ \\
\hline Plantio Direto & 1,57 a2 & $1,69 \mathrm{a} 2$ & $1,44 \mathrm{a} 1$ & $1,42 \mathrm{a} 1$ \\
Plantio Convencional & $1,46 \mathrm{a} 1$ & $1,40 \mathrm{a} 1$ & $1,42 \mathrm{a} 1$ & $1,42 \mathrm{a} 1$ \\
CV\% & 1,02 & 8,36 & 1,34 & 1,20 \\
\hline
\end{tabular}

Legenda: CV, Coeficiente de variação. Médias seguidas pela as mesmas letras e números nas colunas não diferem estatisticamente pelo Teste Tukey a $5 \%$ de probabilidade.

No que se refere à densidade de partículas o sistema plantio direto apresentou valores mais elevados desse parâmetro nas camadas superficiais em relação ao sistema convencional. Nas camadas de $20-30 \mathrm{~cm}$ e $30-40 \mathrm{~cm}$ não houve diferença significativa entre os dois sistemas de manejo avaliados (Tabela 4). Entretanto, vale ressaltar que essa característica apresentou valores bem reduzidos em ambos os sistemas, pois normalmente a densidade de partícula na maioria dos solos variam entre os limites de 2,3 a $2,9 \mathrm{~g} / \mathrm{cm}^{3}$, em média, esse resultado é devido, aos teores de matéria orgânica dos solos da propriedade.

A densidade de partícula $(D p)$ é um parâmetro que está relacionado á composição minerológica e orgânica do solo. Assim, solos que apresentam minerais pesados em grande quantidade, a Dp será maior. Da mesma forma que solos predominantemente orgânicos apresentam valores de densidade de partículas menores. Logo, a densidade de partículas pode ser considerada uma característica bastante estável em relação as modificações repentinas causadas por diferentes sistemas de manejo dos solos.

\section{Porosidade total (Pt)}

$\mathrm{Na}$ Tabela 5 estão apresentadas as informações de porosidade total $(\mathrm{Pt})$ obtidas em diferentes profundidades nos diferentes sistemas de manejo.

TABELA 5 - Porosidade total em \%, obtida em diferentes profundidades nos sistemas plantio direto e convencional.

\section{Plantio Direto Plantio Convencional}

\begin{tabular}{ccccccccc}
$\begin{array}{c}\text { Repetiçõe } \\
\text { s }\end{array}$ & $0-10 \mathrm{~cm}$ & $10-20 \mathrm{~cm}$ & $20-30 \mathrm{~cm}$ & $30-40 \mathrm{~cm}$ & $0-10 \mathrm{~cm}$ & $10-20 \mathrm{~cm}$ & $20-30 \mathrm{~cm}$ & $30-40 \mathrm{~cm}$ \\
\hline R1 & 30,38 & 32,20 & 17,92 & 22,28 & 28,72 & 15,84 & 11,21 & 13,64 \\
R2 & 36,87 & 26,47 & 19,96 & 23,45 & 31,91 & 13,01 & 21,93 & 12,78 \\
R3 & 31,56 & 27,76 & 15,68 & 17,74 & 30,20 & 13,57 & 21,78 & 17,98 \\
R4 & 29,33 & 48,88 & 17,49 & 17,55 & 21,66 & 16,04 & 14,88 & 12,52 \\
R5 & 31,34 & 35,08 & 15,64 & 30,65 & 22,42 & 20,74 & 15,35 & 16,91 \\
\hline
\end{tabular}


A porosidade total refere-se a parte do volume do solo preenchidos pela água e ar, a porcentagem de poros em solos argilosos normalmente variam de 40 a $60 \%$. Quanto a esse atributo físico, nota-se que nas camadas superficiais de $0-10 \mathrm{~cm}$ e 10 $20 \mathrm{~cm}$, o sistema de manejo plantio direto é o ambiente que possui os maiores valores de porosidade total. Sales et al. (2016) atribuíram os maiores valores de porosidade observadas no plantio direto ao efeito proporcionado pelo sistema radicular de culturas antecessoras (milho e braquiária) que após sua morte e decomposição produzem bioporos que contribuem com 0 aumento da macroporosidade e porosidade total, além de fornecer carbono ao solo.

$\mathrm{Na}$ Tabela 6 estão apresentados os resultados a ANOVA de porosidade total $(\mathrm{Pt})$ obtidas em diferentes profundidades nos diferentes sistemas de manejo pelo teste de Tukey.

TABELA 6 - Resultados da média de porosidade total $(\mathrm{Pt})$ em \%, pelo teste de Tukey.

\begin{tabular}{|c|c|c|c|c|}
\hline \multirow[b]{2}{*}{ Tratamentos } & \multicolumn{4}{|c|}{ Profundidades } \\
\hline & $0-10 \mathrm{~cm}$ & $10-20 \mathrm{~cm}$ & $20-30 \mathrm{~cm}$ & $30-40 \mathrm{~cm}$ \\
\hline Plantio Direto & 31,90 a1 & 34,08 a2 & 17,34 a1 & 22,33 a2 \\
\hline $\begin{array}{c}\text { Plantio Convencional } \\
\text { CV\% }\end{array}$ & $\begin{array}{c}26,98 \text { a1 } \\
13,20\end{array}$ & $\begin{array}{c}15,84 \text { a1 } \\
26,83\end{array}$ & $\begin{array}{c}17,03 \text { a1 } \\
20,65\end{array}$ & $\begin{array}{c}14,77 \text { a1 } \\
22,52 \\
\end{array}$ \\
\hline
\end{tabular}

Legenda: CV, Coeficiente de variação. Médias seguidas pela as mesmas letras e números nas colunas não diferem estatisticamente pelo Teste Tukey a $5 \%$ de probabilidade.

A análise dos resultados médios de porosidade total (Tabela 6) mostra que não houve diferenças significativas entre os sistemas de manejo na camada superficial de 0-10 cm e na camada de $20-30 \mathrm{~cm}$, entretanto, em todas as profundidades avaliadas os valores de porosidade total sempre se apresentaram maiores no sistema plantio direto, o que pode ser atribuído aos maiores teores de matéria orgânica proporcionados por este sistema de cultivo. Observa-se, também, que a porosidade total em ambos os sistemas de manejo diminuiu de acordo com a maior profundidade de coleta das amostras.

Ao realizar uma análise conjunta das propriedades densidade do solo (Ds) e porosidade total do solo (Ps), nota-se que nesse sistema de plantio direto de dois anos o solo ainda encontra-se adensado, pois em todas as camadas avaliadas em ambos os sistemas de manejo a porosidade total encontra-se foi inferior a $50 \%$, que é o valor mínimo ideal para as trocas líquidas e gasosas entre o ambiente externo e o solo de forma satisfatória, e considerado crítico para o desenvolvimento radicular da maior parte das culturas em solos argilosos (ANDRADE; STONE, 2009).

Os resultados obtidos nesse estudo corroboram com os obtidos por Bilibio et al. (2010) que constataram que tanto no preparo do solo em sistema convencional quanto no manejo conservacionista (cultivo mínimo e plantio direto) de um Latossolo Vermelho, ocorreu adensamento na superfície do solo, observado através da redução da relação macro/microporos, juntamente com a maior densidade do solo. Solos que apresentam baixos níveis de porosidade, as trocas gasosas são reduzidas e aumenta a concentração de gás carbônico, principalmente nas zonas compactadas, que acaba prejudicando o desenvolvimento do sistema radicular (SILVA et al., 2017).

Em seus estudos Nogueira et al. (2016) observaram que o sistema de plantio direto, de três anos, apresentou menor porosidade total, em relação ao sistema de 
manejo convencional mas segundo estes autores tal condição, persistirá apenas nos primeiros anos de cultivo, deixando de existir com o passar dos anos, uma vez que a deposição frequente de resíduos orgânicos na superfície do solo proporcionada pelo sistema plantio direto resultará na melhoria das características físicas e aumento da porosidade. Freitas et al. (2017) atribuíram a drástica redução da porosidade dos solos cultivados ao aumento da compactação do solo, sendo que a redução do valor desta variável é evidenciada pelo aumento da densidade do solo.

\section{Umidade com base em massa (U)}

$\mathrm{Na}$ Tabela 7 estão apresentadas as informações de umidade com base em massa $(U)$ obtidas em diferentes profundidades nos diferentes sistemas de manejo.

TABELA 7 - Umidade com base massa em g. - $^{-1}$,obtida em diferentes profundidades nos sistemas plantio direto e convencional.

\section{Plantio Direto}

Plantio Convencional

\begin{tabular}{ccccccccc} 
Repetições & $0-10 \mathrm{~cm}$ & $10-20 \mathrm{~cm}$ & $20-30 \mathrm{~cm}$ & $30-40 \mathrm{~cm}$ & $0-10 \mathrm{~cm}$ & $10-20 \mathrm{~cm}$ & $20-30 \mathrm{~cm}$ & $30-40 \mathrm{~cm}$ \\
\hline R1 & 0,36 & 0,38 & 0,31 & 0,29 & 0,32 & 0,29 & 0,28 & 0,29 \\
R2 & 0,37 & 0,35 & 0,31 & 0,30 & 0,33 & 0,27 & 0,31 & 0,30 \\
R3 & 0,36 & 0,38 & 0,31 & 0,29 & 0,32 & 0,27 & 0,30 & 0,31 \\
R4 & 0,36 & 0,50 & 0,31 & 0,30 & 0,31 & 0,29 & 0,29 & 0,29 \\
R5 & 0,36 & 0,40 & 0,30 & 0,30 & 0,31 & 0,30 & 0,29 & 0,29 \\
\hline
\end{tabular}

A umidade com base em massa pode ser definida como a porção da massa da amostra de solo que corresponde à água. Os valores médios de umidade com base em massa no sistema plantio direto variaram de 0,36 a $0,37 \mathrm{~g} \cdot \mathrm{g}^{-1}$, na camada de $0-10 \mathrm{~cm}$ e de 0,35 a 0,50 g. ${ }^{-1}$, na camada subsuperficial de $10-20 \mathrm{~cm}$. Nota-se que o sistema plantio direto, para a mesma profundidade, apresentou valores superiores em relação ao sistema convencional o que pode ser atribuído ao maior teor de matéria orgânica do solo deste sistema.

$\mathrm{Na}$ Tabela 8 estão apresentados os resultados a ANOVA de umidade com base em massa $(U)$ obtidas em diferentes profundidades nos diferentes sistemas de manejo pelo teste de Tukey.

TABELA 8 - Resultados da média de umidade com base em massa (U) em g. $\mathrm{g}^{-1}$, pelo teste de Tukey.

\begin{tabular}{ccccc}
\hline & \multicolumn{4}{c}{ Profundidades } \\
Tratamentos & $\mathbf{0 - 1 0} \mathbf{~ c m}$ & $\mathbf{1 0 - 2 0} \mathbf{~ c m}$ & $\mathbf{2 0} \mathbf{- 3 0} \mathbf{~ c m}$ & $\mathbf{3 0 -} \mathbf{4 0} \mathbf{~ c m}$ \\
\hline Plantio Direto & 0,36 a2 & 0,40 a2 & 0,31 a2 & 0,30 a1 \\
Plantio Convencional & 0,32 a1 & 0,28 a1 & 0,29 a1 & 0,30 a1 \\
CV\% & 1,97 & 12,20 & 2,88 & 2,51 \\
\hline
\end{tabular}

Legenda: CV, Coeficiente de variação. Médias seguidas pela as mesmas letras e números nas colunas não diferem estatisticamente pelo Teste Tukey a $5 \%$ de probabilidade.

Os sistemas de plantio direto (SPD) e convencional (SPC) nas camadas de 0 $10 \mathrm{~cm}, 20-30 \mathrm{~cm}$ e $20-30 \mathrm{~cm}$ apresentaram diferença significativa em relação à umidade com base em massa (U). Em que o sistema de manejo plantio direto apresentou maiores valores de umidade do solo em relação ao sistema convencional, esses resultados podem ser atribuídos aos maiores teores de matéria ENCICLOPÉDIA BIOSFERA, Centro Científico Conhecer - Goiânia, v. 15 n.27; p. 30 2018 
orgânica proporcionados pelo sistema plantio direto. Entretanto, vale ressaltar que a simples determinação da umidade com base em massa (U) não serve como parâmetro indicador dos teores de água presentes no solo e prontamente disponível ao uso pelas plantas, para a obtenção de tais informações é necessária a determinação da umidade do solo com base no volume que é uma variável muito importante para o manejo da irrigação.

\section{Umidade volumétrica (Q)}

$\mathrm{Na}$ Tabela 9 estão apresentadas as informações de umidade volumétrica (Q) obtidas em diferentes profundidades nos diferentes sistemas de manejo.

TABELA 9 - Umidade volumétrica em $\mathrm{cm}^{3} \cdot \mathrm{cm}^{-3}$, obtida em diferentes profundidades nos sistemas plantio direto e convencional.

\section{Plantio Direto}

Plantio Convencional

Repetiçõe $0-10 \mathrm{~cm} \quad 10-20 \mathrm{~cm} \quad 20-30 \mathrm{~cm} \quad 30-40 \mathrm{~cm} \quad 0-10 \mathrm{~cm} \quad 10-20 \mathrm{~cm} \quad 20-30 \mathrm{~cm} \quad 30-40 \mathrm{~cm}$

$$
\mathrm{S}
$$

\begin{tabular}{lllllllll} 
R1 & 0,38 & 0,41 & 0,37 & 0,31 & 0,34 & 0,34 & 0,35 & 0,35 \\
R2 & 0,37 & 0,40 & 0,36 & 0,32 & 0,33 & 0,33 & 0,35 & 0,37 \\
R3 & 0,39 & 0,44 & 0,37 & 0,34 & 0,32 & 0,32 & 0,34 & 0,38 \\
R4 & 0,39 & 0,51 & 0,36 & 0,35 & 0,35 & 0,35 & 0,35 & 0,36 \\
R5 & 0,38 & 0,43 & 0,36 & 0,29 & 0,35 & 0,35 & 0,34 & 0,35 \\
\hline
\end{tabular}

A umidade volumétrica do solo (Q) pode ser definida como a quantidade de água presente em um determinado volume de amostra de solo. A umidade volumétrica está relacionada com a umidade com base em massa ou (gravimétrica). Este é um parâmetro considerado importante no dimensionamento e manejo de sistemas de irrigação.

Os valores médios de umidade volumétrica no sistema plantio direto (Tabela 9) variaram de 0,37 a $0,38 \mathrm{~cm}^{3} \cdot \mathrm{cm}^{-3}$, na camada superficial de $0-10 \mathrm{~cm}$ e de 0,40 a $0,51 \mathrm{~cm}^{3} \cdot \mathrm{cm}^{-3}$, na camada subsuperficial de $10-20 \mathrm{~cm}$. Já Torres et al. (2015) estudando a umidade volumétrica de solos sob sistema plantio direto há doze anos em obtiveram valores de $Q$ variando de 0,14 a $0,18 \mathrm{~cm}^{3} . \mathrm{cm}^{-3}$ na camada superficial $(0-10 \mathrm{~cm})$ e de 0,13 a $0,16 \mathrm{~g} . \mathrm{cm}^{-3}$ na camada subsuperficial $(10-20 \mathrm{~cm})$, e atribuíram estes resultados ao altos índices de compactação observados em seu estudo.

$\mathrm{Na}$ Tabela 10 estão apresentados os resultados a ANOVA de umidade volumétrica $(\mathrm{Q})$ obtidas em diferentes profundidades nos diferentes sistemas de manejo pelo teste de Tukey.

TABELA 10 - Resultados da média de umidade volumétrica $(Q) \mathrm{em} \mathrm{cm}^{3} . \mathrm{cm}^{-3}$, pelo teste de Tukey.

\begin{tabular}{ccccc}
\hline & \multicolumn{4}{c}{ Profundidades } \\
Tratamentos & $\mathbf{0 - 1 0} \mathbf{~ c m}$ & $\mathbf{1 0 - \mathbf { 2 0 }} \mathbf{~ c m}$ & $\mathbf{2 0} \mathbf{- 3 0} \mathbf{~ c m}$ & $\mathbf{3 0} \mathbf{- 4 0} \mathbf{~ c m}$ \\
\hline Plantio Direto & 0,38 a2 & 0,44 a2 & 0,36 a2 & 0,32 a1 \\
Plantio Convencional & 0,34 a1 & 0,34 a1 & 0,35 a1 & 0,36 a2 \\
CV\% & 3,04 & 8,23 & 1,54 & 5,62 \\
\hline
\end{tabular}

Legenda: $\mathrm{CV}$, Coeficiente de variação. Médias seguidas pela as mesmas letras e números nas colunas não diferem estatisticamente pelo Teste Tukey a $5 \%$ de probabilidade.

A análise dos resultados médios de umidade volumétrica (Tabela 10) mostra que houveram diferenças significativas entre os sistemas de manejo nas camadas 
superficiais, onde os valores de umidade volumétrica sempre se apresentaram maiores no sistema plantio direto, o que pode ser atribuído aos maiores teores de matéria orgânica desse sistema. Logo, a quantidade de água armazenada no solo (até uma certa profundidade) é superior no sistema plantio direto, o que pode contribuir para melhor desenvolvimento das plantas e produtividade das culturas.

\section{Resistência a penetração (Rp)}

A Figura 1 apresenta os resultados de resistência à penetração $(\mathrm{Rp})$ ao longo das profundidades estudadas, em ambos os sistemas de manejo.

a) Sistema Plantio Direto (SPD)

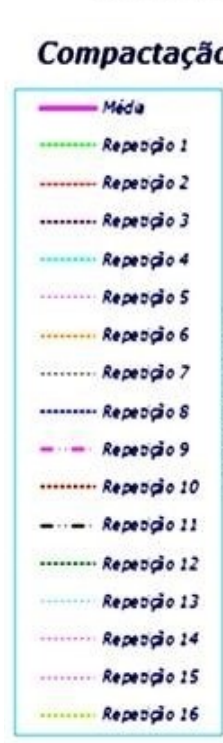

MPa

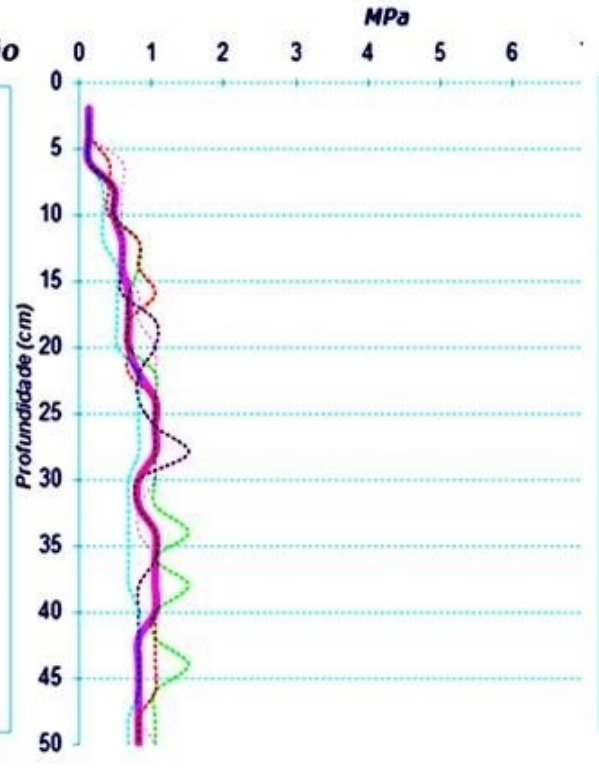

b) Sistema Plantio Convencional (SPC)

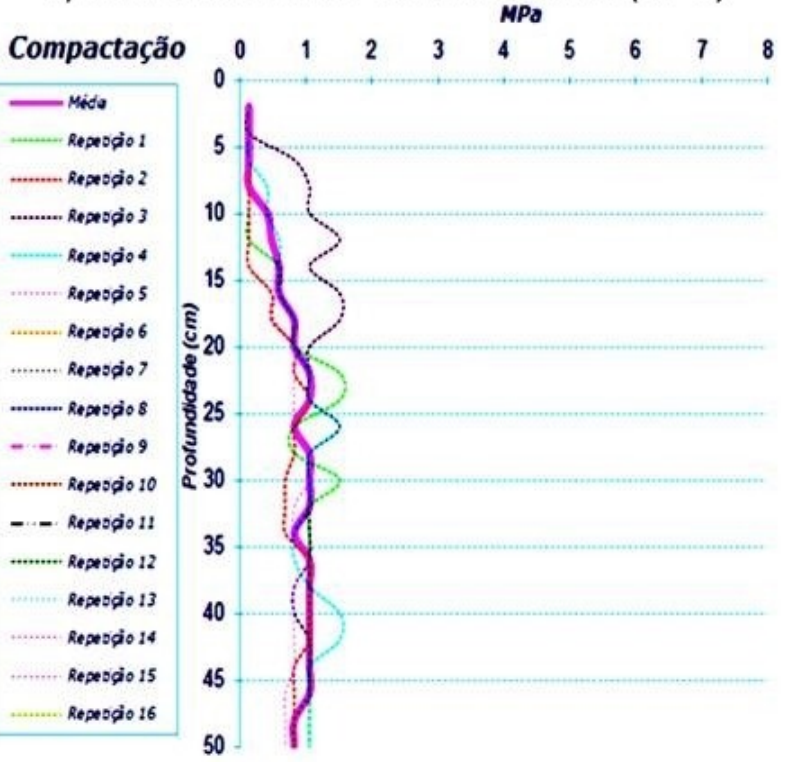

FIGURA 1- Valores de resistência a penetração obtida nos diferentes sistemas de manejo.

$\mathrm{Na}$ camada de 0,0 a $0,10 \mathrm{~m}$, o sistema convencional apresentou resistência à penetração acima de $1 \mathrm{MPa}$ (Megapascal), enquanto que no sistema plantio direto o observado para a mesma profundidade foi de aproximadamente $0,75 \mathrm{MPa}$. Para a camada de 0,10 a $0,20 \mathrm{~m}$, o sistema convencional apresentou resistência à penetração acima de 1,5 MPa, enquanto que no sistema plantio direto o observado para a mesma camada foi de aproximadamente 1,0 MPa.

$\mathrm{Na}$ camada de $0,20-0,30 \mathrm{~m}$ a maioria das repetições no sistema plantio direto apresentaram valores inferiores a $1,0 \mathrm{MPa}$, enquanto que no sistema plantio convencional a maioria das repetições apresentaram valores variando de 1,0 a 1,5 $\mathrm{MPa}$. Deste modo a resistência a penetração em ambos os sistemas de manejo foram classificadas como baixa/moderada de acordo com a classificação apresentada por Girardello et al. (2014).

Resultados obtidos nesse estudo corroboram com os de Colombo et al. (2017) em que a área manejada sob SPD apresentou menor RP entre as camadas superficiais com profundidade $\leq$ à $20 \mathrm{~cm}$. Logo, a resistência a penetração não prejudicou o desenvolvimento do sistema radicular da cultura da soja, por ser inferior ao limite de 2 MPa (SALES et al., 2016). Já Cortez et al. (2014) constataram em seus estudos acréscimo nos valores de RP a partir da camada de 0,10-0,15 m de profundidade e atribuíram esse resultado às estruturas mais densas do solo 
oriundas do sistema convencional anterior que foram inadequadamente corrigidas para implantação do SPD.

Os resultados das pesquisas mostram que nas camadas superficiais a adoção de sistema de cultivo menos agressivos como o plantio direto e a prática de rotação de culturas, favorecem o aumento dos teores de matéria orgânica no solo, e com o passar do tempo, constituem-se em alternativas eficientes para reduzir a compactação dos solos cultivados, pois quanto maior a quantidade de matéria orgânica do solo menor serão os índices de compactação. Silva et al. (2015) obtiveram resultados semelhantes em seu estudo e atribuíram a menor resistência a penetração observada nas camadas superficiais à exploração do sistema radicular das plantas e atividade biológica do solo.

Entretanto, nota-se que nas camadas de profundidades acima de $35 \mathrm{~cm}$ o sistema plantio direto apresentou maior resistência a penetração em relação ao sistema convencional. Os maiores índices de compactação observados nessa profundidade podem estar relacionados à ausência de revolvimento do solo associado ao efeito cumulativo do tráfego mecanizado no sistema plantio direto. A mesma tendência foi observada nos estudos de Torres et al. (2015) que também constataram maiores valores de resistência a penetração, em um sistema de plantio direto de 12 anos, na profundidade entre 0,30-0,40 m, que variaram entre 3,70 e 4,85 $\mathrm{MPa}$ causando efeitos restritivos ao crescimento das plantas.

De acordo com Toigo et al., (2015), o tráfego de máquinas no sistema plantio direto causa degradação estrutural do solo com redução da porosidade total e da macroporosidade, e aumento da densidade do solo e da resistência à penetração. Vale ressaltar que os níveis críticos de resistência à penetração dos solos para o desenvolvimento radicular satisfatório das culturas variam de acordo com o manejo, tipo de solo e a espécie cultivada (CORTEZ et al., 2017; GIRARDELLO et al., 2017). No entanto, podem ser encontrados em muitos estudos valores críticos de resistência à penetração radicular variando entre 1 a 3,5 MPa (LIMA et al., 2010; MORAIS et al., 2014; CORTEZ et al., 2017; ROSSETTI; CENTURION, 2017).

\section{pH do solo e macronutrientes}

A Figura 2 apresenta os resultados da análise química do solo, na profundidade de $0-20 \mathrm{~cm}$, em ambos os sistemas de manejo.

Resultado de Análise Química

\begin{tabular}{|c|c|c|c|c|c|c|c|c|c|c|c|c|c|c|}
\hline \multirow{2}{*}{$\begin{array}{l}\text { Cod. } \\
\text { Lab. }\end{array}$} & \multirow{2}{*}{ Pescriçäo Amostra } & $\mathrm{pH}\left(\mathrm{H}_{2} \mathrm{O}\right)$ & $\mathrm{pH}\left(\mathrm{CaCl}_{2}\right)$ & $\mathrm{P}$ (meh) & $P($ rem) & P(res) & $5 . \mathrm{SO}_{4}{ }^{-2}$ & $\mathrm{~K}^{+}$ & $\mathrm{Ca}^{2+}$ & $\mathrm{Mg}^{2+}$ & $\mathrm{Na}^{+}$ & $\mathrm{Al}^{3+}$ & $\mathrm{H}+\mathrm{Al}$ & \multirow{2}{*}{$\frac{\text { M.O. }}{\mathrm{g} \mathrm{dm}^{-3}}$} \\
\hline & & \multicolumn{2}{|c|}{$\cdot$} & \multicolumn{4}{|c|}{$\mathrm{mg} \mathrm{dm}^{-3}$} & \multicolumn{6}{|c|}{$\mathrm{cmol}_{\mathrm{C}} \mathrm{dm}^{-3}$} & \\
\hline $7 / 2018$ & Amostra Plantio & 5,67 & ns & 5,67 & ns & ns & 4,05 & 0,15 & 4,47 & 0.73 & ns & 0,00 & 2.20 & 24,52 \\
\hline $8 / 2018$ & Amostra Plantio Direto & 5.97 & ns & 19.73 & ns & ns & 6.01 & 0.47 & 7.29 & 0.87 & ns & 0.00 & 2,80 & 34,90 \\
\hline \multirow{2}{*}{$\begin{array}{l}\text { Cod. } \\
\text { Lab. }\end{array}$} & \multirow{2}{*}{ Pescriçäo Amostra } & & SB & CTC & $\mathrm{V}$ & $\mathrm{m}$ & $\mathrm{Ca} / \mathrm{C}$ & ETC & $\mathrm{Mg} / \mathrm{CTC}$ & K/CTC & $\mathrm{Ca} / \mathrm{l}$ & & $\mathrm{Ca} / \mathrm{K}$ & $\mathrm{Mg} / \mathrm{K}$ \\
\hline & & & \multicolumn{2}{|c|}{$\mathrm{cmol}_{\mathrm{c}} \mathrm{dm}^{-3}$} & \multicolumn{2}{|r|}{$\%$} & \multicolumn{4}{|c|}{$\%$} & \multicolumn{4}{|c|}{ Relaçöes } \\
\hline $7 / 2018$ & Amostra Plantio Conve & & 5,35 & 7.55 & 70,86 & 0,0 & 00 & 21 & 9,67 & 1,99 & 6.1 & 12 & 29,80 & 4,87 \\
\hline $8 / 2018$ & Amostra Plantio Direto & & 8,63 & 11,43 & 75.50 & 0,0 & & .78 & 7,61 & 4,11 & 8,3 & & 15,51 & 1,85 \\
\hline
\end{tabular}

FIGURA 2 - Resultados das análises químicas dos solos nos diferentes sistemas de manejo.

Os valores de $\mathrm{Ph}$ em ambos os sistemas de manejo apresentam acidez mediana, por estarem entre a faixa de $5<\mathrm{pH}<6$, nota-se, entretanto que o sistema plantio convencional apresenta maior acidez em relação ao sistema plantio direto, o que pode estar relacionado aos argumentos de Canellas et al., (2003) pois segundo estes autores nos sistemas de plantio convencional o revolvimento constante do solo 
promove a oxidação da matéria orgânica que contribui para o aumento da acidez.

Como se observa nos resultados da amostragem de solo o sistema de manejo plantio direto apresenta teores adequados de todos os nutrientes avaliados em relação ao sistema de manejo convencional, os valores de $\mathrm{Ca}^{2+}, \mathrm{Mg}^{2+}$ são considerados altos, pois apresentam valores acima de 5 , e 0,85 . O teor de $\mathrm{K}^{+}$na camada superficial do plantio direto é considerado satisfatório, pois se encontra acima de 0,30 .

Segundo Costa et al. (2005) os maiores teores de K são resultantes da maior acumulação e ciclagem de nutrientes, oriundos da serrapilheira, sendo que normalmente as plantas mais velhas favorecem em grande parte para a ciclagem e fornecimento deste nutriente por ocasião da maior queda de folhas com contribuição no acúmulo de matéria orgânica.

O teor do elemento fósforo na amostra do sistema plantio direto apresenta-se alto $(16<\mathrm{P}<34)$, enquanto que no sistema convencional apresenta-se baixo próximo a 6 . O motivo do sistema de SPD apresentar maiores valores de fósforo pode estar relacionado ao fato de que neste tipo de manejo é pouco o revolvimento do solo em relação ao sistema de manejo convencional, assim há redução do contato e interação entre os coloide do solo e o íon fosfato, reduzindo a atividade de adsorção do solo (ANGHINONI, 2007).

Rodrigues et al., (2016) estudando os níveis de fósforo em sistema de manejo plantio direto e convencional a longo período, observaram resultados semelhantes com os observados nesse estudo, em que os níveis de fósforo foram superiores no sistema SPD em comparação ao SPC. Santos et al., (2017) também verificaram em seus estudos maiores valores de $\mathrm{P}$ no sistema plantio direto e atribuíram ao fato de que neste tipo de cultivo há pouco revolvimento do solo em comparação aos demais sistemas.

Nota-se também que o valor de soma de bases do tratamento sistema convencional apresentaram-se inferiores aos observados no sistema plantio direto, fato explicado pelos menores teores de $\mathrm{K}+, \mathrm{Ca} 2+$ e $\mathrm{Mg} 2+$ apresentados pelo sistema plantio convencional. Martins et al. (2015) atribuem a acumulação de K, Ca, $\mathrm{Mg}$ e $\mathrm{P}$ nas camadas superficiais no sistema de semeadura direta, tanto ao fato de não haver revolvimento do solo quanto o acúmulo de nutrientes no tecido das plantas cultivadas.

A CTC é uma propriedade físico-química de fundamental importância ao manejo adequado da fertilidade do solo e os sistemas de manejo SPC e SPD apresentaram valores de CTC de 7,55 e 11,43 $\mathrm{cmol} \mathrm{dm}^{-3}$ e Martins et al. (2015) atribuem estes resultados a alta percentagem de argila e, ou, alto teor de M.O dos solos avaliados.

Os valores de SB e V\% também variaram entre os usos e seguem a tendência dos valores descritos para $\mathrm{K}+, \mathrm{Ca} 2+$ e $\mathrm{Mg} 2+$, no qual o sistema plantio direto apresenta maiores valores. Sendo que a saturação por bases (V\%) foi maior que $50 \%$ em ambos os sistemas de manejo na camada superficial de $0-0,20 \mathrm{~m}$, o que pode estar relacionado a matéria orgânica associado efeito residual da adubação e calagem anteriores realizadas nas áreas em estudo.

Os valores obtidos de saturação de alumínio em ambos os sistemas de manejos são considerados nulos (que pode ser resultado da prática da calagem nestas áreas o que promoveu o enriquecimento de $\mathrm{Ca}^{+}$), não havendo a preocupação do seu efeito na redução do desenvolvimento das raízes. Segundo Sousa et al. (2007) altos níveis de m\% podem acarretar a diminuição do tamanho 
das raízes, além de causar o engrossamento afetando significativamente a absorção de água e nutrientes.

\section{Matéria orgânica}

Na Figura 1, observa-se que os teores de matéria orgânica do solo foram reduzidos no tratamento sob sistema convencional, evidenciando que o preparo do solo favorece o aumento da taxa de mineralização da matéria orgânica em razão das perturbações físicas que destroem os compostos macroagregados de $\mathrm{MO}$ expondo a matéria orgânica a ação dos microrganismos decompositores reduzindo seus teores no solo.

De acordo com Cherubin et al. (2015), experimentos de longa duração têm demonstrado que os teores de matéria orgânica do solo são influenciados pelos manejos do solo, havendo incremento dos teores na superfície do solo no SPD em relação ao sistema plantio convencional. O sistema de manejo plantio direto é considerado o sistema que mais favorece a manutenção/preservação da matéria orgânica do solo, em comparação aos outros sistemas de manejo. Segundo Pereira Thomaz (2015) a matéria orgânica é um fator de grande influência sobre as características do solo sendo considerada como um indicador da qualidade ambiental dos solos.

Em seus estudos Souza et al. (2014) observaram aumento significativo da velocidade de mineralização da matéria orgânica no solo em sistema de manejo convencional em relação ao sistema plantio direto e atribuíram os resultados à influência do revolvimento do solo sobre a degradação do $C$ orgânico de fácil oxidação. Melo et al. (2016) também constataram reduções significativas nos teores de matéria orgânica nos macroagregados e amostras de áreas em que foram realizados o sistema de manejo convencional em comparação com o sistema plantio direto.

Outro fator que contribui para a redução dos teores de matéria orgânica nesse sistema de manejo são as adubações realizadas com fertilizantes nitrogenados (sulfato de amônio), que também favorecem a aumento na taxa de mineralização. Por outro lado, embora o sistema plantio direto possua como característica principal o aumento de matéria orgânica na camada superficial, no estudo de Santos et al. (2017) o SPD de três anos se manteve inferior ao sistema de manejo convencional de cinco anos e atribuíram este resultado ao tempo de adoção do sistema. De acordo com Campos et al. (2013), o acréscimo do teor de M.O geralmente não ocorre nos primeiros anos de utilização do SPD, mas seis ou sete anos após a implantação do sistema.

\section{CONCLUSÃO}

1. O sistema de plantio direto de dois anos não apresentou resultados expressivos nas propriedades densidade do solo (Ds) e porosidade total $(\mathrm{Pt})$ em relação ao sistema de plantio convencional.

2. Em todas as profundidades avaliadas os valores de porosidade total sempre se apresentaram maiores no sistema plantio direto.

3. A quantidade de água armazenada no solo (até a profundidade estudada) foi bem maior no sistema de manejo plantio direto. 
4. O sistema de plantio direto apresentou melhores resultados nos atributos químicos, devido ao maior acúmulo de matéria orgânica, alcançando maiores valores de $\mathrm{P}, \mathrm{K}, \mathrm{Ca}$, Mg e V\% na camada superficial.

\section{REFERÊNCIAS}

ANDRADE, R.S.; STONE, L.F. Índice S como indicador da qualidade física de solos do cerrado brasileiro. Revista brasileira de engenharia agrícola e ambiental. v.13 no.4 Campina Grande July/Aug. 2009. Disponível em: < http://www.scielo.br/scielo.php?script=sci_arttext\&pid=S141543662009000400003>doi: http://dx.doi.org/10.1590/S1415-43662009000400003 ANGHINONI, I. Fertilidade do solo e seu manejo em sistema plantio direto. In: NOVAIS, R. F.; ALVAREZ V, V. H.; BARROS, N. F.; FONTES, R. L. F.; CANTARUTTI, R. B.; NEVES, J. C. L. Fertilidade do solo. Viçosa-MG: SBCS, 2007. p. 873-928.

ASSIS, P. C.; STONE, L. F.; MEDEIROS, J. C.; MADARI, B. E.; DE M OLIVEIRA, J.; WRUCK, F. J. Atributos físicos do solo em sistemas de integração lavoura-pecuáriafloresta. Revista Brasileira de Engenharia Agricola e Ambiental-Agriambi, v. 19,

n. $\quad 4$, 2015. Disponivel $\quad$ em https://www.researchgate.net/profile/Luis_Stone2/publication/276119312_Atributos_fi sicos_do_solo_em_sistemas_de_integracao_lavoura-pecuaria-

floresta/links/556c3f4d08aefcb861d634ba.pdf> DOI: http://dx.doi.org/10.1590/18071929/agriambi.v19n4p309-316

ASSIS, R.L \& LANÇAS, K.P. Avaliação dos atributos físicos de um Nitossolo Vermelho distroférrico sob sistema plantio direto, preparo convencional e mata nativa. Revista Brasileira de Ciências do solo, 29:515-522, 2005. Disponível em: < http://www.scielo.br/scielo.php?script=sci_arttext\&pid=S0100-

06832005000400004>doi: http://dx.doi.org/10.1590/S0100-06832005000400004

BALIN, N. M.; ZIECH, A. R.D.; OLIVEIRA, J.P.M.; GIRARDELLO, V.C.; STUMPF, L.; CONCEIÇÃO, P. C. Frações da materia orgânica, indice de manejo do carbono e atributos físicos de um latossolo vermelho sob diferentes sistemas de uso. Scientia Agraria, $\quad$ v. 18, n. 3, 2017.Disponivel em $:<$ https://revistas.ufpr.br/agraria/article/view/53114>. Doi: http://dx.doi.org/10.5380/rsa.v18i3.53114.

BATISTA, P. H. D.; DE ALMEIDA, G. L. P.; TAVARES, U. E.; NASCIMENTO, V. N \& SARMENTO, R. M. Variabilidade espacial de atributos físicos do solo sob colheita mecanizada de capim-buffel no agreste Pernambucano. Enegenharia na Agricultura /Engineering in Agriculture, v. 25, n. 4, p. 307-317, 2017. Disponível em: < https://www.seer.ufv.br/seer/index.php/reveng/article/view/771>. doi: https://doi.org/10.13083/reveng.v25i4.771

BILIBIO, W. D.; CORREAA, G. F.; BORGES, E. N. Atributos físicos e químicos de um Latossolo, sob diferentes sistemas de cultivo. Ciência e Agrotecnologia, v.34, p.817-822, 2010. Disponível em: < http://www.scielo.br/scielo.php?pid=S141370542010000400004\&script=sci_abstract\&tlng=pt>.

doi: http://dx.doi.org/10.1590/S1413-70542010000400004. 
CAMPOS, L. P.; LEITE, L.F.C.; MACIEL, G. A.; BRASIL, E.L.; IWATA, B. F. Estoques e frações de carbono orgânico em Latossolo Amarelo submetido a diferentes sistemas de manejo. Pesquisa Agropecuária Brasileira, Brasília-DF, v. 48, n. 3, p. 304-312, 2013. Disponivel em $:<$ http://seer.sct.embrapa.br/index.php/pab/article/view/12252 > DOI: 10.1590/S0100204X2013000300009.

CANELlAS, L. P.; VElloso, A. C. X.; MARCIANO, C. R.; RAMALHO, J. F. G. P.; RUMJANEK, V. M.; REZENDE, C. E.; SANTOS, G. A. Propriedades químicas de um cambissolo cultivado com cana-de-açúcar, com preservação do palhiço e adição de vinhaça por longo tempo. Revista Brasileira de Ciências do Solo, Viçosa-MG, v. 27, n. 5, p. 935-944, 2003. Disponível em: < http://www.scielo.br/scielo.php? script=sci arttext\&pid=S0100-06832003000500018>. http://dx.doi.org/10.1590/S0100-06832003000500018

CARVALHO, M.A.; RUIZ, H.A.; COSTA, L.M.; PASSOS, R.R.; ARAUJO, C.A.S. Composição granulométrica, densidade e porosidade de agregados de Latossolo Vermelho sob duas coberturas do solo. Revista Brasileira de Engenharia Agrícola e Ambiental, CampinaGrande, PB, v.18, n.10, p.1010-1016, 2014. Disponível em: < http://www.agriambi.com.br/revista/v18n10/v18n10a04.pdf>.

doi: http://dx.doi.org/10.1590/1807-1929/agriambi.v18n10p1010-1016.

CHERUBIN, M. R. ; TONINI EITELWEIN, M. ; FABBRIS, C.; WOLNEI WEIRICH, S.; FERREIRA DA SILVA, R.; SILVA, V.R; BASSO, C. J. Qualidade física, química e biológica de um Latossolo com diferentes manejos e fertilizantes. Revista Brasileira de Ciência do solo, v. 39, n. 2, 2015. Disponivel em :< http://www.redalyc.org/html/1802/180239737029/>. 10.1590/01000683rbcs20140462

COLOMBO, G. A.; LOPES, M. B. S.; DOTTO, M. C.; CAMPESTRINI, R.; DE OLIVEIRA LIMA, S. Atributos físicos de um latossolo vermelho-amarelo distrófico sob diferentes sistemas de manejo no cerrado tocantinense. Campo Digital, v. 12, n. 1 , 2017. Disponivel em :<http://revista.grupointegrado.br/revista/index.php/campodigital/article/view/2068>.

CORTEZ, J. W.; MAUAD, M.; SOUZA, L. C. F.; RUFINO, M. V \& SOUZA, P. H. N. Atributos agronômicos da soja e resistência a penetração em plantio direto e escarificado. Engenharia Agrícola, v. 37, n. 1, 2017. Disponível em: < http://www.scielo.br/pdf/eagri/v37n1/1809-4430-eagri-37-01-0098.pdf>. doi: http://dx.doi.org/10.1590/1809-4430-eng.agric.v37n1p98-105/2017

CORTEZ, J. W.; OLSZEVSKI, N.; PIMENTA, W. A.; PATROCÍNIO FILHO, A.P.; SOUZA, E.B.; NAGAHAMA, H. D. J. Avaliação da intensidade de tráfego de tratores em alguns atributos físicos de um Argissolo amarelo. Revista Brasileira de Ciência do Solo, v.38, n.3, p.1000- 1010, 2014. Disponivel em :< http://www.scielo.br/pdf/rbcs/v38n3/32.pdf >.

COSTA, G. S.; GAMA-RODRIGUES, A. C.; CUNHA, G. M. Decomposição e liberação de nutrientes da serapilheira foliar em povoamento de Eucalyptus grandis no norte fluminense. Revista Árvore, Viçosa-MG, v. 29, n. 4, p. 563-570, 2005. 
Disponível em: <http://www.scielo.br/scielo.php?script=sci_arttext\&pid=S010067622005000400008>. doi: http://dx.doi.org/10.1590/S0100-67622005000400008.

DIAS, M. J.; ALVES, S.F.; FIALHO, E. R.; GOMES, D. O.Probabilidade de ocorrêndia dos atributos químicos em um latossolo sob plantio direto. Revista Caatinga, v. 28, n. 4, 2015. Disponivel em :< http://www.redalyc.org/html/2371/237142689020/>.

EMBRAPA - Empresa Brasileira de Pesquisa Agropecuária. Centro Nacional de Pesquisas de Solos (Rio de Janeiro). Manual de métodos de análises de solo. 2.ed. Rio de Janeiro: EMBRAPA, 1997. 212p.

FAVARATO, L. F.; SOUZA, J. L.; GALVÃO, J. C. C.; DE SOUZA, C. M.; GUARÇONI, R. C. ATRIBUTOS QUÍMICOS DO SOLO SOBRE DIFERENTES PLANTAS DE COBERTURA NO SISTEMA PLANTIO DIRETO ORGÂNICO. Brazilian Journal of Sustainable Agriculture, v. 5, n. 2, 2015. Disponivel em :< http://www.rbas.com.br/index.php/rbas/article/view/312>. http://dx.doi.org/10.21206/rbas.v5i2.312.

FREITAS, L.; OLIVEIRA, I. A.; SILVA, L. S.; FRARE, J. C. V.; FILLA, V. A.; GOMES, R. P. INDICADORES DA QUALIDADE QUÍMICA E FÍSICA DO SOLO SOB DIFERENTES SISTEMAS DE MANEJO. Revista Unimar Ciências, v. 26, n. 1-2, 2017. Disponivel em :< http://ojs.unimar.br/index.php/ciencias/article/view/511>.

GIRARDELLO, V.C.; AMADO, T. J.C., SANTI, A. L.; CHERUBIN, M. R.; KUNZ, J.; TEIXEIRA, T.G. Resistência à penetração, eficiência de escarificadores mecânicos e produtividade da soja em Latossolo argiloso manejado sob plantio direto de longa duração. Revista Brasileira de Ciência do Solo, v. 38, n. 4, 2014. . Disponivel em :< http://www.scielo.br/pdf/rbcs/v38n4/20.pdf >

GIRARDELLO, V. C.; AMADO, T. J. C.; SANTI, A. L.; LANZANOVA, M.E \& TASCA, A. Resistência do solo a penetração e desenvolvimento radicular da soja sob sistema plantio direto com tráfego controlado de máquinas agrícolas. Scientia Agraria, v. 18, n. 2, 2017. Disponível em: < http://revistas.ufpr.br/agraria/article/view/50693>. doi: http://dx.doi.org/10.5380/rsa.v18i2.50693.

GOMES, R. L. R.; SILVA, M. C.; COSTA, F. R.; JUNIOR, A. F.L.; OLIVEIRA, I. P \& SILVA, D. B. Propriedades físicas e teor de matéria orgânica do solo sob diferentes coberturas vegetais. Revista Eletrônica Faculdade Montes Belos, v. 9, n. 1, 2015. Disponível em: < http://www.fmb.edu.br/revistaFmb/index.php/fmb/article/view/167>.

LIMA, C.L.R.; REINERT, D.J.; REICHERT, J.M.; SUZUKI, L.E.A.S. Produtividade de culturas e resistência à penetração de Argissolo Vermelho sob diferentes manejos. Pesquisa Agropecuária Brasileira, v. 45, n. 1, p. 89-98, 2010. Disponível em: < http://www.scielo.br/scielo.php?pid=S0100204X2010000100012\&script=sci_abstract\&tlng=pt $>$. doi: http://dx.doi.org/10.1590/S0100-204X2010000100012. 
LIMA, R.P.; SILVA, A.R.; OLIVEIRA, D.M.S. Análise de trilha de atributos físicos na resistência à penetração de um latossolo amarelo. Revista de Agricultura Neotropical, Cassilândia, MS, v.1, n.1, p.65-74, 2015. Disponível em: < http://periodicosonline.uems.br/index.php/agrineo/article/view/216>.

LÓPEZ-GARRIDO, R.; MADEJÓN, E.; LEÓN-CAMACHO, M.; GIRÓN, I.; MORENO, F.; MURILLO, J.M. Reduced tillage as an alternative to no-tillage under Mediterranean conditions: acase study. Soil and Tillage Research, v.140, p.40-47, $2014 . \quad$ Disponivel em :<=https://www.sciencedirect.com/science/article/pii/S0167198714000300 > DOI: 10.1016/j.still.2014.02.008.

MARTINS, E. C. A.; PELUZIO, J. M.; DE OLIVEIRA JUNIOR, W. P.; TSAI, S. M., NAVARRETE, A. A.; MORAIS, P. B. Alterações dos atributos físico-químicos da camada superficial do solo em resposta à agricultura com soja na várzea do Tocantins. Biota Amazônia (Biote Amazonie, Biota Amazonia, Amazonian Biota), v. 5, n. 4, p. 56-62, 2015. Disponivel em :< https://periodicos.unifap.br/index.php/biota/article/view/1362>. Doi: http://dx.doi.org/10.18561/2179-5746/biotaamazonia.v5n4p56-62

MELO, G. B.; PEREIRA, M. G.; PERIN, A.; GUARESCHI, R. F \& SOARES, P. F. C. Estoques e frações da matéria orgânica do solo sob os sistemas plantio direto e convencional de repolho. Pesquisa Agropecuária Brasileira, v. 51, n. 9, p. 15111519 , 2016.

Disponível em:

https://seer.sct.embrapa.br/index.php/pab/article/view/22374>.

MORAES, M.T.; DEBIASI, H.; CARLESSO, R.; FRANCHINI, J.C; SILVA, V.R. Limites críticos da resistência à penetração do solo em um Eutrudox. Revista Brasileira de Ciência do Solo, v.38, n.1, p.288-298, 2014. Disponível em: < http://www.scielo.br/scielo.php?pid=S0100-

06832014000100029\&script=sci_abstract\&tlng=pt $>$.

doi:

http://dx.doi.org/10.1590/S0100-06832014000100029.

NEGREIROS NETO, J.V.; SANTOS, A. C.; GUARNIERI, A.; SOUZA, D. J.A.T.; DARONCH, D. J.; DOTTO, M. A.; ARAÚJO, A. S. Variabilidade espacial de atributos físico-químicos de um Latossolo Vermelho-Amarelo distrófico em sistema plantio direto. Semina: Ciências Agrárias, v. 35, n. 1, 2014.Disponivel em :< http://www.redalyc.org/html/4457/445744139016/>. Doi: 10.5433/16790359.2014v35n1p193.

NIKKEL, M \& LIMA, S.O. Spatial comparison of soil penetration resistance between two central pivots. Applied Research \& Agrotechnology, v. 10, n. 1, p. 93-102, 2017. Disponível em: https://revistas.unicentro.br/index.php/repaa/article/view/4687>. doi: 10.5935/PAeT.V10.N1.10

NOGUEIRA, K. B.; ROQUE, C. G.; BORGES, M. C. R. Z.; TROLEIS, M. J. B.; BARRETO, R. F.; OLIVEIRA, M. P. Atributos físicos do solo e matéria orgânica sob dois manejos e efeito residual da aplicação de calcário e gesso agrícola. Revista de la Facultad de Agronomía, v. 115, 2016. Disponivel em 
:<http://sedici.unlp.edu.ar/bitstream/handle/10915/54168/Documento_completo.pdfPDFA.pdf?sequence=1>.

OLIVEIRA, D.M.S.; LIMA, R.P.; VERBURG, E.E.J. Qualidade física do solo sob diferentes sistemas de manejo e aplicação de dejeto líquido suíno. R. Bras. Eng. Agríc. Ambiental, v.19, n.3, p.280-285, 2015. Disponível em:< http://www.agriambi.com.br/revista/v19n03/v19n03a13.pdf>. DOI: http://dx.doi.org/10.1590/1807-1929/agriambi.v19n3p280-285.

PEREIRA, A. A.; THOMAZ, E. L. Atributos químicos do solo em áreas sob diferentes sistemas de uso e manejo no município de reserva-PR. Caminhos de Geografia, v. 16, $\quad$ n. $\quad 55, \quad 2015 . \quad$ Disponivel $\quad$ em http://www.seer.ufu.br/index.php/caminhosdegeografia/article/view/28327>.

RODRIGUES, M.; PAVINATO, P. S.; WITHERS, P.J.A.; TELES, A. P.B.; HERRERA, W.F.B. Legacy phosphorus and no tillage agriculture in tropical oxisols of the Brazilian savanna. Science of the Total Environment. Amsterdam, v. 542, n.15, p. 1050-1061, 2016.

ROSSETTI, K.V.; CENTURION, J. F. Compactação em Latossolos e suas relações com o crescimento radicular do milho. REVISTA AGRO@ MBIENTE ON-LINE, v. 11, n. 3, p. 181-190, 2017. Disponível em: < https://revista.ufrr.br/agroambiente/article/view/3845>. doi:

http://dx.doi.org/10.18227/1982-8470ragro.v11i3.3845.

SALES, R.P.; PORTUGAL, A.F.; MOREIRA, J. A.A.; KOITI KONDO, M.; PEGORARO, R.F. Qualidade física de um Latossolo sob plantio direto e preparo convencional no semiárido. Revista Ciência Agronômica, v. 47, n. 3, 2016. Disponivel em :< http://ccarevista.ufc.br/seer/index.php/ccarevista/article/view/4037>

SANTOS, O. F.; SOUZA, H. M.; OLIVEIRA, M. P.; CALDAS M. B.; ROQUE C. G. Propriedades químicas de um Latossolo sob diferentes sistemas de manejo. Revista de Agricultura Neotropical, Cassilândia-MS, v. 4, n. 1, p. 36-42, jan./mar. 2017. Disponivel em https://periodicosonline.uems.br/index.php/agrineo/article/view/1185>.

SILVA, M. A. S.; DA; MAFRA, Á. L.; ALBUQUERQUE, J. A.; BAYER, C.; MIELNICZUK, J. Atributos físicos do solo relacionados ao armazenamento de água em um Argissolo Vermelho sob diferentes sistemas de preparo. Ciência Rural, v.35, p.544-552, 2005. Disponível em: < http://www.scielo.br/scielo.php?pid=S010384782005000300009\&script=sci_abstract $>$. doi: http://dx.doi.org/10.1590/S0103-84782005000300009.

SILVA, G.F.; SANTOS, D.; SILVA, A.P.; SOUZA, J.M.; Indicadores de qualidade do solo sob diferentes sistemas de uso na mesorregião do agreste paraibano. Revista Caatinga, Mossoró, v. 28, n. 3, p. 25 - 35, 2015). Disponível em:< http://www.scielo.br/pdf/rcaat/v28n3/1983-2125-rcaat-28-03-00025.pdf>.

http://dx.doi.org/10.1590/1983-21252015v28n303. 
SILVA, M. P.; A.R.F. O.; SÁ, M. E.; ABRANTES, F. L.; BERTI, C. L. F. ; DE SOUZA, L. C. D. Plantas de cobertura e qualidade química e física de Latossolo Vermelho distrófico sob plantio direto. Revista Brasileira de Ciências Agrárias, v. 12, n. 1, p. 60-67, 2017.Disponivel em :< http://www.redalyc.org/pdf/1190/119050448010.pdf>. Doi: 10.5039/agraria.v12i1a5424.

SOARES, M. D. R.; CAMPOS, M. C. C.; OLIVEIRA, I. A.; CUNHA, J. M.; SANTOS, L. A. C.; FONSECA, J. S.; SOUZA, Z. M. Atributos físicos do solo em áreas sob diferentes sistemas de usos na região de Manicoré, AM. Revista de Ciências Agrárias/Amazonian Journal of Agricultural and Environmental Sciences, v. 59, n. 1, p. 9-15, 2016. Disponível em: $<$ https://periodicos.ufra.edu.br/index.php/ajaes/article/view/2020>. Doi: http://dx.doi.org/10.4322/rca.2020.

SOUSA, D. M. G.; MIRANDA, L. N.; OLIVEIRA, S. A. Acidez do solo e sua correção. In: NOVAIS, R. F.; ALVAREZ V., V. H.; BARROS, N. F.; FONTES, R. L. F.; CANTARUTTI, R. B.; NEVES, J. C. L. Fertilidade do solo. Viçosa-MG: SBCS, 2007. p. $203,-274$.

SOUZA, R.F.; FIGUEIREDO, C.C.; MADEIRA, N.R.; ALCÂNTARA, F.A. Effect of management systems and cover crops on organic matter dynamics of soil under vegetables. Revista Brasileira de Ciência do Solo, v.38, p.923-933, 2014b. Disponível em: < http://www.scielo.br/scielo.php?script=sci_arttext\&pid=S0100$06832014000300024>$.

doi: $10.1590 / \mathrm{S} 0100-06832014000300024$.

TAVARES, U.E.; MONTENEGRO, A.A.A.; ROLIM, M.M.; SILVA, J.S.S.; VICENTE, T.F.S.; ANDRADE, C.W.L. Variabilidade espacial da resistência à penetração e da umidade do solo em Neossolo Flúvico. Water Resources and Irrigation Management, Cruz das Almas, BA, v.3, n.2, p.79-89, 2014. Disponível em: < https://www.researchgate.net/profile/Ue_Tavares/publication/291100352_Variabilida de_espacial_da_resistencia_a_penetracao_e_da_umidade_do_solo_em_Neossolo_ Fluvico/links/56a771e108ae860e02555f67/Variabilidade-espacial-da-resistencia-apenetracao-e-da-umidade-do-solo-em-Neossolo-Fluvico.pdf>. doi: 10.19149/23166886/wrim.v3n2p79-89

TOIGO, S.; BRAIDA, J. A.; POSSENTI, J. C.; BRANDELERO, E. M \& BAESSO, M. M. Atributos físicos de um nitossolo vermelho cultivado com trigo, em sistema plantio direto, submetido à compactação e escarificação1/physical attributes of an oxisol cropped with wheat in no-tillage system, subjected to compaction and scarification. Revista Engenharia na Agricultura, v. 23, n. 1, p. 19, 2015. Disponível em: < http://www.seer.ufv.br/seer/index.php/reveng/article/view/516/359>. doi: DOI: https://doi.org/10.13083/reveng.v23i1.516.

TORRES, J. L. R.; DE ALMEIDA COSTA, D. D.; SILVA NETO, O. F.; ARAÚJO, A. S., SILVA, V. R.; SILVA VIEIRA, D. M. AVALIAÇÃO DA RESISTÊNCIA À PENETRAÇÃO E DENSIDADE DO SOLO NUM LATOSSOLO SOB SEMEADURA DIRETA HÁ DOZE ANOS-10.14688/1984-3801/gst. v8n1p131-140. GLOBAL SCIENCE AND TECHNOLOGY, v. 8, n. 1, 2015. Disponivel em :< 
https://rv.ifgoiano.edu.br/periodicos/index.php/gst/article/view/694>.

Doi:

http://dx.doi.org/10.14688/1984-3801/GST.V8N1P131-140. 